\title{
Exploring the Relationship between Summary Writing Ability and Reading Comprehension: Toward an EFL Writing-to-Read Instruction
}

\author{
Samiha Mokeddem \\ Djillali Liabes University of Sidi Bel Abbes, Algeria; samiha_mokeddem@yahoo.fr \\ Samira Houcine \\ Djillali Liabes University of Sidi Bel Abbes, Algeria; samhouc.univ@gmail.com
}

Doi:10.5901/mjss.2016.v7n2s1p197

\begin{abstract}
Summary writing both boosts and measures reading comprehension. When learners write a summary of a reading, they are supposed to demonstrate their comprehension of the target text through writing; they are required to attend more closely to what they are reading to be able to communicate it in their own words. Summary writers are therefore involved in an active process where reading and writing are closely interrelated, and readers' inability to summarize a reading is an indicator of inappropriate comprehension. Based on the strong connection between reading and writing, the current research work is an attempt to examine the extent to which EFL learners' summary writing ability correlates with their comprehension of the original reading material. In order to carry on the study, sixty EFL university students at intermediate level of language proficiency were involved. The participants taught by the teacher researcher in the English Language Department of the Faculty of Letters, Languages and Arts, at Djillali Liabes University of Sidi Bel Abbes, first received an explicit instruction on summarizing, then were subject to a text summarizing assignment, then to a post-summarizing reading comprehension test involving the same text used in the summarizing assignment. Students' written summaries as well as their written answers to the comprehension questions were collected to be scored. The findings revealed that there existed a positive correlation between summary writing ability and reading comprehension.
\end{abstract}

Keywords: EFL, reading-writing relationship, writing-to-read, summarizing.

\section{Introduction}

Reading for academic purposes is closely connected to writing (Leki \& Carson, 1997; Rosenfeld, Leung \& Oltman, 2001). They - reading and writing - go hand in hand as the former precedes and informs the latter and the latter shapes and directs the former. Students are usually required to read materials that provide them with valuable information in relation to their target disciplines. They might jot down some annotations in the text's margins, paraphrase or quote from the source text, synthesize relevant information, write a research paper, answer a series of post-reading questions in writing, or turn to any other act of writing that helps prevent their reading from proceeding in a haphazard way (Zamel, 1992; Blanton, 1993; Hirvela, 2007). And even though the focus in L2 reading-writing connection research is mostly on readingfor-writing strategies, writing from sources can also be approached from a writing-to-read perspective (Hirvela, 2007). Indeed, writing before, during, or after reading serves reading and readers in a variety of ways just as reading sustains writing (Leki, 1993; Lent, 1993; Kauffman, 1996; Faust, 2000). Summarizing, one of the primary writing-to-read strategies in academic settings, offers tremendous opportunities for writing to enhance reading (Kintsch \& Van Dijk, 1978; Trites \& McGroarty, 2005). Many investigations in L1 settings have demonstrated that summary writing improves reading comprehension of texts (Kim, 2001; Keck, 2006), L2 research has also found substantial impact of summarization on the reading comprehension of EFL learners (Baleghizadeh \& Babapur, 2011; Trabasso \& Bouchard, 2002; Shokrpour, Sadeghi \& Seddigh, 2013). However, research has seldom been done to include summary writing as part of the instruction to ascertain whether it can actually lead to better reading comprehension in EFL settings (Huang, 2014).The current study was conducted to investigate the effects of EFL students' summary writing ability in measuring their reading comprehension. It was an attempt to shed light on the relationship between reading and writing from a writing-to-read perspective. 


\section{Theoretical Background}

\subsection{Reading-Writing Relationships}

During decades, reading and writing were kept separate both in theoretical perspectives and in instructional practices. However, with the advent of the 'cognitive rode of learning' in the mid-1970s, reading was perceived as consisting of a complex set of coordinated mental processes. Hence the information the reader brings to the text as well as the information found in the text were claimed to influence each other to produce comprehension (Tierney \& Pearson, 1994).

From the mid-1970s to the 1980s, researchers conducted a number of seminal studies on reading-writing relationships in L1 contexts. These studies gave birth to three major interrelated hypotheses: the directional hypothesis, the non-directional hypothesis, and the bidirectional hypothesis (Grabe, 2003; Ferris \& Hedgcock, 2005).The directional perspective presupposes that the connection between reading and writing is directional suggesting two lines of research direction: reading-to-writing model (Eckhoff, 1983) and writing-to-reading model (Taylor \& Berkowitz, 1980; Belanger, 1987).

Although the directional model has its strong advocates, further research on cognitive processes offered an alternative means of describing how reading and writing may be related in L1 namely the non-directional hypothesis. This hypothesis can be viewed as an interactive model, where "reading and writing are said to derive from a single underlying proficiency, the common link being that of the cognitive process of constructing meaning" Carson (1990:90). Therefore, transfer can occur in either direction: from reading to writing or from writing to reading.

The early part of the 1990s was marked by Rosenblatt's (1988) transactional theory of reading and writing. He suggested the term 'transaction' to designate "relationships in which each element conditions and is conditioned by the other in a mutually-constituted situation". This third hypothesis about the reading-writing relationships was called "the bidirectional hypothesis' (Shanahan, 1984), claiming that reading and writing are interactive as well as interdependent.

Though these models of reading-writing connections centred on reading and writing within the L1 context, they have served as the foundation from which much of the L2 reading-writing connections research has been conducted.

To date, L2 research seems to have reached a consensus on this issue supporting the notion of directionality (Asencion, 2008; Plakans, 2008; Yoshimura, 2009. Hirvela (2007:36) contended that a complete L2 reading-writing connections model building "is problematic because a true model of this type must account, simultaneously, for the inclusion of reading in a theory of writing instruction and a theory of writing in reading instruction". Building a model that binds these two directions (reading to write and writing to read) into one unified whole is "an elusive business" (Hirvela, 2007:36), particularly as we must take into consideration, in the L2 field, the characteristics that separate it from the L1 field. In that sense, Grabe (2001:25) stated: "One of the most consistent implications of the two decades of research on reading and writing relations is that they should be taught together and that the combination of both literacy skills enhances learning in all areas".

\subsection{Writing to Read}

Approaching reading-writing relations from a directional perspective is the most relevant model for pedagogical concerns as it helps teachers decide whether reading should lead to writing or whether writing should lead to reading in their instruction (Eisterhold, 1990). Accordingly, Kroll (1993:75) claimed "teaching writing without teaching reading is not teaching writing at all".

Similarly, the use of writing to enhance reading has also generated a great deal of debate among those searching for methodologies that increase improvement in reading proficiency. Indeed, writing before, during, or after reading, was shown to assist reading and readers in a number of ways (Leki, 1993; Kauffman, 1996). Many studies have proved the contribution that writing gives to a reader (Taylor \& Beach, 1984; Petrosky, 1982; Wittrock, 1983). Fotovatian \& Shokrpour (2007) found that students relying on strategies involving writing like note-taking, summarizing, understanding text-structure are shown to be better readers than those who do not. Synthesizing is probably a hard task even for the best readers if they rely on reading merely. Hence, "the more effective approach would be to synthesize these texts through some kind of analytic writing." (Hirvela, 2007:94). When synthesizing, the student can also turn to writing paraphrases of key sentences and quoting from the source texts too as helpful ways to strengthen reading (Campbell, 1990). All this can facilitate students' reading of texts through the medium of writing. 


\subsection{The Effects of Summary Writing on Reading Comprehension}

Summary writing is one of the primary contact points between reading and writing in academic settings. Such an instance of academic behaviour where reading and writing are intimately interrelated (Hidi \& Anderson, 1986) has received much attention in the literature. This interest has evolved as researchers have attempted to describe the strategies readers use when processing and summarizing a passage. Learners who summarize their reading are involved in a process of reproduction that includes: "(a) thorough comprehension of the original source; (b) selection of the text's most salient information; (c) deletion of less-than-essential information; (d) comprehension and integration of the selected information; and (e) arrangement of selected material in a way that reflects the rhetorical structure of the original." (Ferris \& Hedgcock, 2005:106). That is why, there is considerable evidence that summary writing both encourages and measures reading comprehension (Friend, 2001; Thiede \& Anderson, 2003). Summarizing, then, cultivates active reading and minimizes passive reading, which influences comprehension. It is thus an inherent part of comprehension. Indeed, while involved in summarizing, learners are self-testing their reading comprehension and applying strategies to remedy comprehension breakdowns (Palinscar, 1986; Thiede \& Anderson, 2003). In fact, summarizing has been identified as a more authentic method for assessing what readers do or do not understand about a text than traditional tests of reading comprehension (Kintsch et al., 2000).

It is worth noting, however, that writing an effective summary is a difficult task that is rarely done satisfactorily, even by students at university level (Grellet, 1999; Duke \& Pearson, 2002). This might be attributed to the fact that many teachers wrongly assume that students know how to summarize, and hence, they do not teach them how to do so (Hill, 1991). Yet, research has indicated that the skill of summarization needs to be explicitly taught in order for students to turn into effective and critical readers (Taylor \& Beach, 1984, Cordero-Ponce, 2000).

\section{The Present Study}

\subsection{Participants}

The sample for the present study consisted of sixty students from the first-year LMD students enrolled in the English Licence degree proposed by the English Language Department of the Faculty of Letters, Languages and Arts, at Djillali Liabes University of Sidi Bel Abbes, during the academic year 2013-2014. They were baccalaureate holders of mixed gender, aged between 19-36 years old, coming mainly from the literature and foreign languages streams of secondary school. These students have studied English, their second foreign language, during seven years prior to entering university.

The choice for the current study was determined by the fact that the researcher has been teaching the 'Comprehension and Written Expression' module through an integrated reading-writing instructional approach since 2013. She wanted to investigate the potential benefits of instructional practices involving a connection between reading and writing. During the whole year of instruction, students were involved in many activities involving reading and writing. Right from the beginning, it was made clear to them that the core/main objectives of the module were to make them able to understand written language, produce their own pieces of writing, and of course, aware of the relationships between these two basic language skills. Many reading-to-write and writing-to-read classroom activities were planned, yet the present study is concerned merely with the act of 'summarizing' approached from a writing-to-read perspective.

\subsection{Research Instruments and Procedures}

Research has shown that one of the most effective procedures for increasing comprehension is to have students write a summary of what they have read (Graham \& Hebert, 2010). Based on the notion above, the current investigation tends to obtain empirical evidence that serves either to support or reject the claim that the reader's ability to summarize a text contributes to his/her overall comprehension of the target reading material. The scope of the study is to examine the relationship between EFL students' summary writing ability and their reading comprehension. More specifically, differences in reading comprehension performance among EFL students of different summary writing ability will be identified in an effort to shed light on the reading-writing connection from a writing-to-read perspective.

To fulfil this aim a descriptive correlational research methodology suitable to describe and discover links or associations between variables drawn from a single group of research participants was utilized and a set of steps was required. The participants first received an explicit instruction on summarizing. This step was planned, for the researcher intended to remove the presupposition that all students already acquired the skill of summarizing. Moreover, such a direct 
rule-driven procedural instruction was needed knowing that summary writing is a highly complex reading-writing activity that does not develop on its own. By the end of the instruction, the students were subject to a text summarizing assignment, then to a post-summarizing reading comprehension test involving the same text used in the summarizing assignment. The reading comprehension test assigned was meant to assess students' overall understanding of the target passage. Finally, students' summaries as well as their written answers to the comprehension questions were collected to be scored. And in order for the researcher to analyse, compare, and interpret the results, each student was required to write his/her name at the top of both his/her written summary, and his/her written answers to the reading comprehension questions.

Two scores will then be given to each participant - one for each of the two variables (i.e., summary writing and reading comprehension). This would enable the researcher to identify the relationship between each participant's summary writing ability and his/her reading comprehension - by determining how change in one variable is correlated with a change in the other variable.

It is worth noting here that relationships in correlational studies are usually examined with no potential cause-andeffect linkage. Yet, it is possible to establish a certain cause and effect relationship between two correlated variables. Indeed, two of the major factors that Rovai, Baker and Ponton (2013) suggested to obtain evidence of a cause and effect relationship in correlational studies were relied on in the present investigation - to prove that summary writing ability has an influence on reading comprehension performance (as the study adopted a writing-to-read directional perspective). The two factors are:

- Temporal precedence of the cause over the effect - in the current study, participants received an explicit instruction on summary writing and were assigned to write a summary before being assessed for their reading comprehension performance.

- Theoretical basis for the cause and effect relationship - there exists a theory-based causal mechanism that explains the relationship between summary writing ability (being the cause) and reading comprehension ability (being the effect), as reported in 'section 2.3' belonging to the theoretical background of the present study.

\subsection{Explicit Instruction on Summarizing}

This explicit instructional practice was implemented following the teaching steps below adapted from Irwin's model (2006) of direct instruction:

a. Explanation: as a starting point, the researcher defined and explained the strategy of summarizing. Besides, the researcher tried to make the students aware of the merits of such a strategy. Then, students received a rule sheet with rules for how to write a good summary (see appendix A).

b. Modelling: at this stage, the instructor distributed a text to the students, and started modelling and demonstrating the strategy of summarizing using think-aloud procedure (i.e. the vocalization of the internal thought process) while reading that sample text. When the teacher finished vocalizing the process of summarizing, students were given a copy of the product or the written summary of text produced by the instructor.

c. Transferring (Guided Practice): as students became aware of the stages involved in the process of summarizing, the teacher instructed them to work in pairs or small groups to summarize another text. The instructor walked around the class to provide guidance when necessary, and asked students guiding questions to scaffold their use of the target strategy. When students finished writing their summaries, they were instructed to read and self-evaluate their final products by asking themselves questions like: does our summary include all of the important details? Did we leave out details that were important? Did we combine some details or events that go together? Did we put the ideas in our own words? Are our details in logical order? Did we write in complete sentences?

d. Application: after being involved in the above guided practice, students were given an opportunity to apply the strategy independently writing a summary of a new text individually with no scaffolding.

It is worth noting that explicit instruction on summarizing that participants received lasted four sessions of one hour and a half each. The papers of the summary writing assignment of the independent practice phase were collected to be read and scored by the researcher.

\subsection{Text summarizing assignment}

As mentioned above, participants were given a text to be read and summarized in the last phase of the explicit 
summarizing instruction they were involved in. The text used for the assignment was of intermediate level difficulty, and it was an expository one on purpose, as research has shown that summarization instruction is beneficial in working with expository texts. The sixty summaries were collected to be evaluated on the extent to which students effectively convey the relevant information of the original reading material accurately, clearly and concisely using their own words but without introducing their own ideas and opinions.

Indeed, each summary was scored based on holistic criteria rather than on specific dimensions of summary writing. Unlike the analytic rubric that gives separate scores for each criteria, the holistic rubric gives a single score for each summary. The use of holistic rubrics is probably more appropriate when performance tasks require students to create some sort of response and where there is no definite correct answer (Nitko, 2001). The scores were assigned on a 4-point scale.

\subsection{Reading Comprehension post-summarizing test}

As explained earlier, the same sample of participants took a one-hour reading comprehension test at the end of this investigation. This post-summarizing test consisted of the same expository text used in the summarizing assignment and a set of six comprehension questions to which students had to provide answers. Questions one and six of the test aimed at assessing learners' ability to skim for the main idea of the text and therefore, provide a suitable title to the text as well. Questions two to five assessed learners' ability to scan for details and locate specific information in the text. Question four, however, assessed their ability to infer by associating text information or text topic to their personal knowledge. Participants' answers were collected to be scored by the researcher using an analytic scoring scale. Each question is worth 2 points, and thus, if all his/her responses are both accurate and complete, one will get a total of 12 points as a score. If a question is partially answered, the student may get 1 point out of 2 for it. Scores less than 6 were classified as limited, scores between 6 and 8 were classified as intermediate, and scores above 8 were classified as good.

The test sought to measure students' overall understanding of the text they have summarized. The aim was to determine the correlation between the written summary and the comprehension questions' responses performed by each participant.

\section{Results \& Discussion}

Based on the findings of the holistic rubric used by the researcher, no summary out of the 60 written summaries reached the score of 4 (advanced), 22 summaries scored 3 (good), 23 summaries scored 2 (intermediate), and 15 summaries scored 1 (limited).

No student was, then, able to write a summary that meets all the criteria of competence (i.e., a 4 summary) and this indicated that summarizing is a skill that needs to be practised frequently if one is to become proficient. Nevertheless, a 3 summary is still good even though it is not excellent. The 22 students who reached such a score revealed a generally accurate reading of the text, as they were able to convey the main idea and the most significant details supporting it. Besides, their summaries were generally written in their own words and most ideas were presented in a coherent manner. Moreover, they exhibited general control of written language except some minor mistakes in grammar and spelling. It is worth nothing also that for some students among those 22, introducing one sentence or two expressing their opinion was the main cause that prevented their summaries from reaching the 4 score. All in all, the 22 participants scored 3 were classified as good summarizers of the target text, and were, therefore, considered to have comprehended the reading material appropriately.

The 23 students who scored 2 were classified by the researcher as intermediate summarizers showing a partial understanding of the text they had read. The main idea of the original text was not specifically stated in their writing, some supporting information was missing, and some irrelevant information was included. Moreover, the noticeable borrowing of some sentences directly from the original text indicated marginal interpreting and paraphrasing skills. They also showed some weaknesses in grammar and conventions.

For the last category of students' summaries (the 15 summaries scored 1), however, they were considered as limited in all areas of competence, either because the content was inaccurate, poorly written, or seriously disorganized, or because students largely or completely imitated the source material copying whole paragraphs directly from it. This revealed that those 15 participants had not attended closely to the material being read, or that they were struggling to understand it. Indeed, it is assumed that their inability to restate what they have read into their own words is an indicator of their lack of comprehension of that reading.

On the other hand, the results of the reading comprehension test were as follows: 43 students scored above 8 out 
of 12 (good reading comprehenders), 5 participants scored between 6 and 8 (intermediate reading comprehenders), while 12 participants were identified as limited reading comprehenders showing a poor performance in the test and scoring below 6 (scores between 1 and 4).

The 43 respondents identified as good reading comprehenders made convenient finding about the main idea discussed in the text, and were successful in giving suitable titles to the target reading material through their answers to question one and six of the test respectively. This means that they had understood the main point the writer attempted to express. Besides, most of them (30 students) succeeded in identifying specific details within the text ignoring unrelated information as all their answers to question two, three, and five were complete and accurate. This implies that they were involved with the text they were reading. The results gathered also showed that 28 students could infer information sought by question four of the test appropriately, and this was a reflection of active reading. Overall, their performance in the reading comprehension test showed that they were actively thinking and working to create meaning from what they read.

As far as intermediate comprehenders are concerned, they showed a partial identification of the overall main idea of the reading material as they included too many details in their answers to question one of the test. Nevertheless, their choices of the text's title were suitable through their answers to question six. They had difficulty identifying some specific details from the text required through question two, three and five, and they were all able to read between the lines, figuring out information implied or not directly stated in the text, and made, therefore, appropriate inferences while answering question four of the test.

It is worth noting that limited reading comprehenders were all unable to extract the main idea of the text and failed in some way to find out the appropriate answer to question one of the test as their suggestions were either too general or too detailed. The same remark can be made about the titles they had proposed for the reading material. Such a poor performance revealed a specific difficulty to summarize the main concern of the text. It also showed an inability to keep the meaning in mind as they read. Moreover, the scores they have to question two, three, and five of the test, revealed that they were far from being successful in locating specific details that are supposed to be relevant information in the text. Indeed, no one of those 12 respondents reached the full score awarded for answering all those three questions correctly. Furthermore, it was noticed that the majority of them (9 students out of 12) could not infer information sought by question four of the test. They failed to apply the active comprehension strategy of inferring as they could not monitor their comprehension or engage in productive thinking while reading.

In an attempt to determine the correlation between students' ability to produce a written summary of the target reading material and their overall understanding of the reading, each participant's summary writing performance was compared to his/her performance in the reading comprehension test. The findings are illustrated through the table and the diagram below.

Representative table of participants' summary writing performance and their reading comprehension scores

\begin{tabular}{|c|c|c|c|}
\hline $\begin{array}{ll}\text { Summary Writing Performance } & \text { Reading Comprehension score }\end{array}$ & {$[0-6[$} & {$[6-9[$} & {$[9-13[$} \\
\hline Limited summary & 12 & 3 & 0 \\
\hline Intermidiate summary & 0 & 2 & 21 \\
\hline Good summary & 0 & 0 & 22 \\
\hline
\end{tabular}

Representative diagram of participants' summary writing performance and their reading comprehension scores

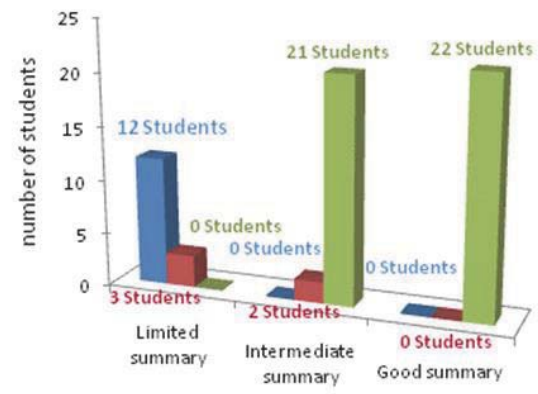

- $[0-6[$ Limited reading comprehension scores

[ $[6-9$ [Intermediate reading comprehension scores

= $[9-13$ [Good reading comprehension scores 
First, all of the 22 students who were able to produce good written summaries reached good scores (scores above 8 out of 12) in the reading comprehension test as well. This supports the assumption that if a reader has the ability to reduce a text to its main points while deleting its irrelevant details and stating the condensed version in his/her own words, he/she is considered to have a good grasp of the target reading material.

Second, no one of the 23 students who produced intermediate written summaries of the original text showed a limited performance in the reading comprehension test as no one scored below 6 out of 12. Indeed, 21 of them obtained good scores while a minority ( 2 students) got intermediate scores (between 6 and 8 out of 12) in the test. It can be said accordingly that the majority of the intermediate summarizers displayed an appropriate understanding of the target reading through their answers to the reading comprehension test. In fact, they all successfully formed the main idea of the reading and were able to identify relevant information in the text. It might be assumed then that the lack of some supporting information, and the inclusion of some irrelevant details in their written summaries do not necessarily imply that they were struggling to understand the text. Instead, this intermediate performance in summary writing might be attributed to their lack of concentration on the task. It seems that they did not take their time to attend closely to the reading material before launching into writing. Such a lack of involvement in the task of summarizing was also revealed through the direct borrowing of some sentences from the original text.

Finally, 12 students who wrote limited summaries of the reading scored badly in the reading comprehension test as well (below 6 out of 12), 3 students among them showed an intermediate performance in the test, while no one was able to reach good scores. Accordingly, those who were not able to summarize the target text appropriately showed an inappropriate comprehension of the reading as shown through their answers to the comprehension test.

The bond between students' summary writing ability and their overall reading comprehension performance is expressed in the graph that follows.

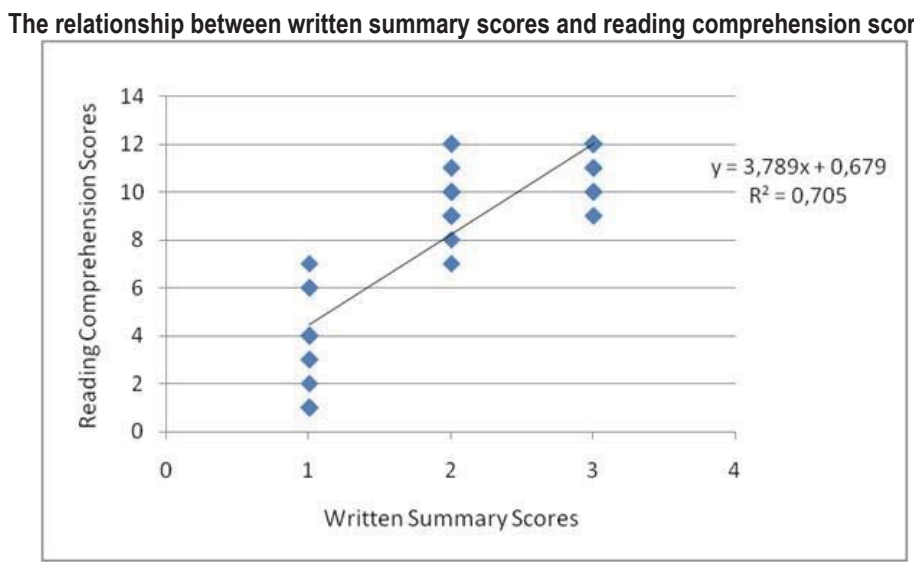

The director coefficient $(3,789)$ of the regression line is positive. Thus, the covariance between the two variables is positive indicating a positive correlation between the scores of written summaries and that of reading comprehension. Besides, the coefficient of determination $\mathrm{R}^{2}$ is an indicator which allows measuring the quality of a correlation. The later is considered to be strong if $0.5<R^{2}<1$ whereas it is considered to be weak if $0<R^{2}<0,5$. In our case, $R^{2}=0.7052>0.5$ and this reveals a strong bond between the scores of written summaries and that of reading comprehension.

Moreover, since the coefficient of determination $\mathrm{R}^{2}=0.705$, we can say that $70,5 \%$ of the total variation of the scores of comprehension is explained by the link between the scores of written summaries and that of reading comprehension which clearly explains such a strong correlation between the two variables as well.

\section{Conclusion}

Our goal was to examine the extent to which EFL learners' summary writing ability correlates with their reading comprehension of the material being summarized. This was an attempt to look at the contribution writing makes to reading and to illustrate why it is important to link reading and writing in EFL instruction. The findings indicate that being able to write an effective summary of a reading is a strong predictor of reading comprehension. In other words, if students 
can summarize a text appropriately, they are often considered to have comprehended the reading appropriately. However, if they are not able to summarize the reading material, they are supposed to have an inadequate grasp of it. A strong positive correlation has, thus, been revealed between the two variables. Accordingly, we may come to the conclusion that if EFL learners are helped to work on their summarizing skills, they will become more active, critical readers of materials they are exposed to in the target language. Yet, it is worth mentioning that summarizing is not an easy task. It requires a lot of training and enough practice to be mastered. Moreover, creating a good summary implies not only a complete comprehension of the reading material, but also a necessary writing ability to create a new version of the source text. Such writing ability can be enhanced through exposure to reading. Ultimately, reading and writing are closely interrelated, and integrating them in instruction is definitely of great benefits to EFL learners.

\section{References}

Asención, Y. (2008). Investigating the reading-to-write construct. Journal of English for Academic Purposes, 7, 140-150.

Baleghizadeh, S., \& Babapur, M. (2011). The effect of summary writing on reading comprehension and recall of EFL students. New English Reading Association Journal, 47 (1), 44-57.

Belanger, J. (1987). Theory and research into reading and writing connections: A critical review. Reading-Canada-Lecture, 5, 10-18.

Blanton, L. L. (1993). Reading as performance: Reframing the function of reading. In J. G. Carson \& I. Leki (Eds.), Reading in the composition classroom: Second language perspectives (pp. 234-242). Boston: Heinle \& Heinle.

Campbell, C. (1990). Writing with other's words: Using background reading text in academic compositions. In B. Kroll (ed.): Second Language Writing: Research Insights for the Classroom (pp. 211-230). Cambridge: Cambridge University Press.

Carson, J. (1990). Reading-writing connections: toward a description for second language learners. In Kroll, B. (ed.) Second Language Writing: Research Insights for the Classroom (pp. 88-107). Cambridge: Cambridge University Press.

Cordero-Ponce, W. L. (2000). Summarization instruction: Effects on foreign language comprehension and summarization of expository texts. Reading Research and Instruction, 39 (4), 329-350.

Duke, N., \& Pearson, D. (2002). Effective practices for developing reading comprehension. In A. Farstrup \& S. Samuels (Eds.). What research has to say about reading instruction. (3rd ed.) (pp. 205-242) Newark, DE: International Reading Association.

Eckhoff, B. (1983). How reading affects children's writing. Language Arts, 60, 607-616.

Eisterhold, J. (1990). Reading-writing connections: Toward a description for second language learners. In B. Kroll (Ed.), Second language writing: Research insights for the classroom (pp. 88 -101). New York: NY: Cambridge University Press.

Faust, M. (2000). Reconstructing familiar metaphors: John Dewey and Louise Rosenblatt on literary art as experience. Research in the Teaching of English, 35, 9-34.

Ferris, D. \& Hedgcock, J. S. (2005). Teaching ESL Composition: Purpose, Process, and Practice (2nd ed). Mahwah, NJ: Lawrence Erlbaum Associates.

Fotovatian, S. \& Shokrpour, N. (2007). A Comparison of the Efficacy of Reading Comprehension Strategies on EFL Readers' Comprehension; Journal of College Reading and learning 16(1), pp. 213-230.

Friend, R. (2001). Effects of strategy instruction on summary writing of college students. Contemporary Educational Psychology 26(1), 324.

Grabe, W. (2001). Notes toward a theory of second language writing. In T. Silva \& P. Matsuda (eds), On Second Language Writing (pp.39-57). Mahwah, NJ: Lawrence Earlbaum Erlbaum Associates.

Grabe, W. (2003). Reading and writing relations: second language perspectives on research and practice. In Kroll, B. (ed.), Exploring the Dynamics of Second Language Writing (pp. 242-262). Cambridge: Cambridge University Press.

Graham, S., \& Hebert, M.A. (2010). Writing to read: Evidence for how writing can improve reading. A Carnegie Corporation Time to Act Report. Washington, DC: Alliance for Excellent Education.

Grellet, F. (1999). Developing Reading Skills: A Practical Guide to Reading Comprehension Exercise. Cambridge: Cambridge University Press.

Hidi, S, \& Anderson, V (1986). Producing written summaries: task demands, cognitive operations, and implications for instruction. Review of Educational Research, 56(4), 473-493.

Hill, M. (1991). Writing summaries promotes thinking and learning across the curriculum -- but why are they so difficult to write?Journal of Reading, 34(7), 536-639.

Hirvela, A. (2007). Connecting reading and writing in second language instruction. Ann Harbor: University of Michigan Press.

Huang, W. C. (2014). The effects of multi-media annotation and summary writing on Taiwanese EFL students' reading comprehension. The Reading Matrix, 14, 136-153.

Irwin, J (2006). Teaching reading comprehension processes (3rded). Boston. MA: Allyn \& Bacon.

Kauffman, R. A. (1996). Writing to read and reading to write: Teaching literature in the foreign language classroom. Foreign LanguageAnnals, 29, 396-402.

Keck, C. (2006). The use of paraphrase in summary writing: A comparison of L1 and L2 writers. Journal of Second Language Writing, 15(4), 261-278.

Kim, S. (2001). Characteristics of EFL readers' summary writing: A study with Korean university students. Foreign Language Annals, 34 (6), 569-581. 
Kintsch, E., Steinhart, D., Stahl, G., LSA Research Group, Cindy Matthews, and Ronald Lamb (2000). Developing summarization skills through the use of LSA-based feedback. Interactive Learning Environments , 8, 87-109.

Kintsch, W. \& Van Dijk, T.A. (1978). Toward a model of text comprehension and production. Psychological Review, 85 (5), 363-394.

Kroll, B. (1993). Teaching writing IS teaching reading: Training the new teacher of ESL composition. In J. G. Carson \& I. Leki (Eds.), Reading in the composition classroom: Second Language Perspectives, 61-81. Boston: Heinle\&Heinle.

Leki, I. (1993). Reciprocal themes in ESL reading and writing. In J. G. Carson \& I. Leki (Eds.), Reading in the composition classroom: Second language perspectives, (pp. 9-32). Boston: Heinle \& Heinle.

Leki, I. \& Carson, J. (1997) "Completely different worlds": EAP and the writing experiences of ESL students in university courses. TESOL Quarterly. 31 (1), 39-70.

Lent, R. (1993). "I can relate to that ...": reading and responding in the writing classroom. College Composition and Communication, 44, $232-240$.

Mertler, C. A. (2001). Using performance assessment in your classroom. Unpublished manuscript, Bowling Green State University.

Nitko, A. J. (2001). Educational assessment of students (3rd ed.). Upper Saddle River, NJ: Merrill.

Olson, C.B. (2011). The reading/writing connection: Strategies for teaching and learning in the secondary classroom, (3rd ed.). New York: Allyn \& Bacon/Pearson.

Petrosky, A. R. (1982). From story to essay: reading and writing. College Composition and Communication, 23, 19-36.

Plakans, L. (2008). Comparing composing processes in writing-only and reading-to-write test tasks. In Assessing Writing, 13, 111-129.

Rosenblatt, L. (1988). Writing and reading: The transactional theory. Reader, 20, 7-31.

Rosenfeld, M., Leung, S., \& Oltman, P. (2001). The reading, writing, speaking, and listening tasks important for academic success at the undergraduate and graduate levels (TOEFL Monograph Series MS-21). Princeton, NJ: Educational Testing Service.

Rovai, A. P., Baker, J. D., \& Ponton, M. K.. (2013). Social science research design and statistics: A practitioner's guide to research methods and SPSS analysis (2nd ed.). Chesapeake, VA: Watertree Press.

Shanahan. T. (1984). Nature of the reading-writing relation: An exploratory multivariate analysis. Journal of Educational Psychology, 76 (3). 466-477.

Shokrpour, N., Sadeghi, A., \& Seddigh, F. (2013). The effect of summary writing as a critical reading strategy on reading comprehension of Iranian EFL learners. Journal of Studies in Education, 3(2), 127-138.

Taylor, B. M. (1982). A summarizing strategy to improve middle grade students' reading and writing skills. The Reading Teacher, 36(2), 202-205.

Taylor. B. M.,\& Beach. R.W. (1984). The effects of text structure instruction on middle-grade students' comprehension and production of expository text. Reading Research Quarterly, 19 (2), 134-146.

Taylor, B. M., \& Berkowitz, S. (1980). Facilitating children's comprehension of content material. In M.L. Kamil \& A. J. Moe (Eds.), Perspectives on reading research and instruction. Twenty-ninth yearbook of the National Reading Conference. Washington, DC: National Reading Conference.

Thiede, K. W., \& Anderson, M. C. M. (2003). Summarizing can improve metacomprehension accuracy. Educational Psychology 28(2), $129-160$

Tierney, R. J., \& Pearson, P. D. (1994). Toward a composing model of reading. In J. M. Jemsen (Ed.), Composing and comprehending (pp. 33-45). Urbana, IL:National Council of Teachers of English.

Trabasso, T., \& Bouchard, E. (2002). Teaching readers how to comprehend texts strategically. In C. Block \& M. Pressley (Eds.), Comprehension instruction: Research-based best practices (pp. 176-200). New York: Guilford Press.

Trites, L., \& McGroarty, M. (2005). Reading to learn and reading to integrate: new tasks for reading comprehension tests? Language Testing, 22, 174-210.

Williams, J.P. (1988). Identifying Main Ideas: A Basic Aspect of Reading Comprehension. Topics in Language Disorders, 8 (3): 1-13.

Wittrock, M. C. (1983). Writing and the teaching of reading. Language Arts, 60, 600-606.

Yoshimura, F. (2009). Effects of connecting reading and writing and a checklist to guide the reading process on EFL learners' learning about English writing. Procedia Social and Behavioral Sciences, 1, 1871-1883.

Zamel, V. (1992). Writing one's way into reading. TESOL Quarterly, 26, 463-485.

\section{Appendices}

\section{Appendix A: Steps to writing a Summary}

1. Read the whole text you are summarizing carefully and with full concentration at least twice to make sure you understand it.

2. Highlight the main idea.

3. Identify the portions of the text that support the main idea; underline these sections (main points/key supporting ideas).

4. Cross out useless information (minor details) such as illustrations, quotations, etc. from the original text.

5. Paraphrase the key points (rewrite them using your own words; do not quote anything word-for-word).

6. Combine your sentences using transitional words or phrases.

7. Your summary should be shorter than the original text. It reduces to about one third of its original size.

8. Do not add anything beyond the author's ideas (do not include your opinion). 